\title{
Infection Control in dental practice for chair-side Assistants in Tanzania
}

\author{
Mwangosi, IEAT ${ }^{1}$, Lema $\mathbf{P}^{\mathbf{1}}$, \\ ${ }^{1}$ Muhimbili National Hospital, School of Assistant Dental Officers. \\ Mwangosi, IEAT, Lema P, \\ Infection Control in dental practice for chair-side Assistants in Tanzania. Tanz Dent J 2010, 16 (2):55-57
}

\begin{abstract}
Rationale: In Tanzania Dental Auxiliaries are used as dental chair-side assistants without formal training. This way of recruiting dental health personnel has an inherent weakness that may adversely affect infection control in dental practice. To redress this weakness, the School of Assistant Dental Officers at Muhimbili National Hospital, Tanzania initiated a course aimed at training dental auxiliaries to upgrade their knowledge, attitudes and skills on asepsis and infection control in dental practice. Aim of the course: The aim of the course was to train and orient the chair-side assistants on cross-infection control in dental practice. The scope and implementation of the course: This is a two weeks course that covers principles and procedures for infection control in dental practice. The participants are guided through a series of lectures, seminars, demonstrations and hands on practical sessions. Pre- and post course evaluation is done and upon successful completion of a course, a certificate of participation is offered. Outcome of the course: Twenty-one participants from across Tanzania have successfully completed the course from 2005 to 2008. Pre- and post course evaluation consistently indicated an increase in level of knowledge and skills for infection control in dental practice among participants. Conclusion: It is hereby concluded that this course improved the knowledge and skills of participants. Recommendations: A formal evaluation of the impact of this course to the performance of the participants in asepsis and infection control in dentistry is needed. Hospitals that have not sent their dental auxiliaries to this course are encouraged to do so.
\end{abstract}

Key Words: Dental auxiliaries, continuing education, infection control in dental practice

Correspondence: Dr. Mwangosi, IEAT, Muhimbili National Hospital, School of Assistant Dental Officers, P. O. Box 66521 Dar es Salaam. ieatmwangosi@yahoo.com

\begin{abstract}
Introduction
Ever since independence in 1961, Tanzania has been using Dental Health Attendants (DHA) and Dental Health Auxiliaries as chair-side assistants to assist dental practitioners as an alternative to trained dental nurses (1). The dental health auxiliary and/or dental health attendant is health personnel who is recruited without prior training in health/dental courses, and undergo on-the-job training locally on how to assist the dental practitioners. In majority of cases, these are usually recruited from the pool of young Tanzanians who just completed their primary school education; therefore they have limited exposure to education, let alone science discipline which are important in dental education.
\end{abstract}

Recruiting health care workers who have not undertaken a relevant rigorous training has inherent weaknesses that may affect quality assurance in health care delivery. First, they are put in practice before they have shown that they can perform their duties satisfactorily. Secondly, the on job training is difficult to standardize, therefore similar persons in this category are likely to have different knowledge, attitude and practical skills depending on the dental practitioner who trained them. Thirdly, the level of knowledge expected of a chair side assistant to the dental practitioner is likely to be beyond that acquired at primary school education. As the Common interview writer puts it: "the certification is one of the proofs with an aspirant which allows the manager to make sure the candidate's ability, through a very competent way. Certification does not mean merely printed paper or card, signed by some authority, telling about your expertise. Rather certification is a process in which you prove your technical skills through the series of tests" (2). Therefore expecting the dental health auxiliary and/or dental health attendant recruited without prior training in health/dental courses to adhere to asepsis protocols and maintain asepsis in dental practice is a bit too ambitious.

The practice of recruiting untrained dental health auxiliaries might have been perceived as satisfactory in previous years because of lack of knowledge on the prevalence of hepatitis causing viruses in Tanzania. Currently there is an accumulated knowledge on the high prevalence rates of hepatitis B $( \pm 70 \%)$ and $\mathrm{C}$ virus $( \pm 5 \%)$ in Tanzania (3-7), as well 
as their adverse effects to the functions of the liver because they have been shown to be major risk factors for hepatocellular carcinoma $(8,9)$. In addition to high prevalence of hepatitis causing viruses in Tanzania, HIV infection has been on increase during the last 20 years. By year 2010, the prevalence of HVI seropositivity among Tanzanians was reported to be around $7 \%(10,11)$. Since Tanzania has untrained chair-side-assistants who may not have knowledge, attitudes and skills required for prevention of cross-infection in dental practice, there is an urgent need to train them in the efforts of controlling the spread of HBV, HCV and HIV infection. This is not an easy task and requires commitment from the government and all institutions overseeing the health of Tanzanians because there are over 300 dental auxiliaries countrywide, all employed under permanent basis (12).

In view of the above facts, the School of Assistant Dental Officers at Muhimbili National Hospital, Tanzania initiated a course aimed at undertaking a rigorous training for these dental auxiliaries to upgrade their knowledge and skills on assisting the dental practitioners and raise their attitudes and know-how on asepsis and infection control in dental practice. This initiative is aimed at improving their effectiveness as dental surgery assistants who will in turn improve the quality dental services rendered in respective clinics.

\section{The scope of the course}

The course is of two weeks duration with the following eight objectives that must be attained by each participant at the end of the course: (1) describe the common infections related to dentistry; (2) explain how cross infection occurs in a dental clinic; (3) identify operational surfaces which need attention in controlling cross infection in a dental clinic; (4) prepare sterile dental instruments and materials ready for surgical operative procedure; (5) prepare sterile operational surfaces in dental surgeries; (6) prepare oral health education scheme for dental patients; (7) handle dental patients before, during and after clinical treatment; and (8) give oral health education to patients.

To achieve the eight stated objectives, participants are guided through a series of lectures, seminars, demonstrations and hands on practical sessions. The topics covered during the course include infectious diseases in dental practice; disease transmission in dental practice; dental instruments, materials and equipment; preparation of dental materials for use in the dental treatment procedures; sterilization of dental instruments, asepsis in dental surgery; handling of dental patients; health care waste management in dental practice, especially on how to protect patients and health care workers from infection and protecting the environment and communities from pollution.

\section{Implementation of the course}

Brochures for the two weeks course on Oral Infection Control were prepared and disseminated to all District, Regional and Referral Hospitals as well as the office of the Chief Dental Officer of the Ministry of Health and Social Welfare. The brochure described the course objectives, methods of instructions, eligibility for enrollment and fee for the course and up-keep allowance for the participants. In addition, the course venue and the deadline for submission of the application form for each year were also stipulated in the brochure. Dental Health Auxiliaries and Dental Health Assistants from across Tanzania's public and private dental clinics registered for the two weeks short course based at the Muhimbili National Hospital (MNH) under School of Assistant Dental Officers each year in 2005 to 2008. English and Swahili are instruction languages for basic and applied dental sciences - anatomy, dental materials, aseptic dental clinic management, waste disposal and national guidelines on infection prevention and control in healthcare services. Exposure to dental clinics and visits to waste disposal sites within MNH is done. Facilitators from within and outside $\mathrm{MNH}$ were invited to run the course through lectures, lecture-discussion, and demonstration hands on practice in Muhimbili dental clinics. Pre- and post course evaluation was done and upon completion, a certificate of participation was offered.

\section{Outcome of the course}

Twenty-one participants from across Tanzania have successfully undergone the course from 2005 to 2008. Average percent scores for the pre- and post course evaluation were respectively 53 and 65 for the year 2006 and 66 and 81.3 for the year 2007, indicating an increase in level of knowledge and skills for infection control in dental practice. Verbal communication from heads of clinics at which those trained under this course are working, indicate that there is marked improvement in oral health related knowledge, attitudes and skills among the course graduates. 


\section{Conclusion}

Based on the results of the pre- and post course evaluation, it can be concluded that this course improved the knowledge and skills of the dental auxiliary staff that successfully completed the course.

\section{Future outlook and recommendations}

The encouraging results from the pre- and post course assessment point to the need to (1) continue offering the course to all the dental auxiliary staff, (2) conduct a formal evaluation to assess the impact of this course at the dental clinics where the participants are working, (3) review the course and register it for accreditation to raise its impact on the remuneration of its graduates, and (4) encourage all regional and district councils to set aside funds for their dental auxiliaries to attend this course.

\section{Acknowledgement}

The authors wish to acknowledge the contribution of Dr Frank Fubusa from Tanga Dental Therapist School, who first expressed the need to have such a course to Dr Philip Lema from Muhimbili School of Assistant Dental Officers who picked the idea. The authors thank the employers who sponsored the participants to this course.

\section{References}

1. Muya RJ, Rambusch E, Fejerko O, Hobdel $\mathrm{MH}$, Norman S. Changing and developing dental health services in Tanzania, 1980-2000. Ministry of Health/DANIDA, Dar es salaam, Tanzania 1984.

2. http://commoninterview.com/Interview_Advic e/importance-of-certification-for-the-careerand-job-search-1.

3. Haukenes G, Shao JF, Mbena E, Rustad S. Hepatitis B virus markers in the population of Dar es Salaam, Tanzania. J Infect. 1987; 15:183-8.

4. Miller WC, Shao JF, Weaver DJ, Shimokura GH, Paul DA, Lallinger GJ. Seroprevalence of viral hepatitis in Tanzanian adults. Trop Med Int Health. 1998; 3:757-63.
5. Menendez C, Sanchez-Tapias JM, Kahigwa E, Mshinda H, Costa J, Vidal J, Acosta C, LopezLabrador X, Olmedo E, Navia M, Tanner M, Rodes J, Alonso PL. Prevalence and motherto-infant transmission of hepatitis viruses B, C, and $\mathrm{E}$ in Southern Tanzania. J Med Virol. 1999; 58:215-20.

6. Stark K, Poggensee G, Höhne M, Bienzle U, Kiwelu I, Schreier E. Seroepidemiology of TT virus, GBC-C/HGV, and hepatitis viruses $\mathrm{B}$, $\mathrm{C}$, and $\mathrm{E}$ among women in a rural area of Tanzania. J Med Virol. 2000; 62:524-30.

7. Nagu TJ, Bakari M, Matee M. Hepatitis A, B and $\mathrm{C}$ viral co-infections among HIV-infected adults presenting for care and treatment at Muhimbili National Hospital in Dar es Salaam, Tanzania. BMC Public Health. 2008 19; 8:416.

8. Yang JD, Roberts LR. Hepatocellular carcinoma: A global view. Nat Rev Gastroenterol Hepatol. 2010; 7:448-58.

9. Song IH, Kim KS. Current status of liver diseases in Korea: hepatocellular carcinoma. Korean J Hepatol. 2009; 15 Suppl 6:S50-9.

10. Mapingure MP, Msuya S, Kurewa NE, Munjoma MW, Sam N, Chirenje MZ, Rusakaniko S, Saugstad LF, de Vlas SJ, StrayPedersen B. Sexual behaviour does not reflect HIV-1 prevalence differences: a comparison study of Zimbabwe and Tanzania. J Int AIDS Soc. 2010 16;13:45.

11. Kumogola Y, Slaymaker E, Zaba B, Mngara J, Isingo R, Changalucha J, Mwidunda $\mathrm{P}$, Kimaro D, Urassa M. Trends in HIV \& syphilis prevalence and correlates of HIV infection: results from cross-sectional surveys among women attending ante-natal clinics in Northern Tanzania. BMC Public Health. 2010 Sep 13;10:553.

12. COHU Compiled list of the oral health care workers in Tanzania. Central Oral Health Unit, Ministry of Health and Social Welfare, United Republic of Tanzania; 2007. 